\title{
OBSERVATÓRIO DE TURISMO E LAZER NA REGIÃO TURÍSTICA BAIXADA VERDE: EXPERIÊNCIA E RESULTADOS
}

\author{
Observatorio de turismo y ocio de la Región Turística Baixada Verde: experiencia y resultados \\ Tourism and leisure observatory of the Baixada Verde Tourist Region: experience and results \\ Isabela Fátima Fogaça \\ Universidade Federal Rural do Rio de Janeiro (UFRRJ), \\ Brasil \\ isafog@hotmail.com \\ DOI: https://doi.org/10.18472/cvt.20n1.2020.1754 \\ Redalyc: http://www.redalyc.org/articulo.oa? \\ id $=115462634005$
}

\section{Teresa Cristina de Miranda Mendonça}

Universidade Federal Rural do Rio de Janeiro (UFRRJ),

Brasil

tecaturismo@yahoo.com.br

Maria Angélica Maciel Costa

Universidade Federal Rural do Rio de Janeiro (UFRRJ),

Brasil

mangelicamc@hotmail.com

Catramby Teresa Cristina Viveiros

Universidade Federal Rural do Rio de Janeiro (UFRRJ),

Brasil

teresacatramby@gmail.com

Recepción: 17 Agosto 2019

Aprobación: 20 Febrero 2020

\section{Resumo:}

Historicamente, a Baixada Fluminense, localizada na região metropolitana do estado do Rio de Janeiro, é conhecida pela segregação político-territorial, o que atua na autoestima de sua população e a retira do imaginário turístico do estado mais visitado do Brasil. A partir de 2017, ações de política pública vêm sendo desenvolvidas para mudar a conotação daquele território, tendo como foco a riqueza natural ali presente. Este artigo buscou discutir a importância do intercâmbio de conhecimento entre Academia e a Sociedade na área do Turismo e do Lazer, a partir da experiência do Observatório de Turismo e Lazer da Região Turística Baixada Verde, sediado na UFRRJ, criado a partir desse novo contexto regional. De natureza descritiva e qualitativa, valeu-se da pesquisa documental e bibliográfica e do relato de experiências. Como resultado, em dois anos de atuação do Observatório, a inventariação da oferta turística de seis municípios, a atualização do inventário de um município e pesquisas junto aos moradores já permitem análises e considerações, e repercussão positiva do trabalho que vem sendo feito, tendo como base a nova imagem que se quer construir para a região.

Palavras-chave: Desenvolvimento Regional do Turismo, Baixada Fluminense, Baixada Verde, Observatório de Turismo, Estado do Rio de Janeiro.

\section{ReSUMEN:}

Históricamente, la Baixada Fluminense, ubicada en la región metropolitana del estado de Río de Janeiro, es conocida por su segregación político-territorial, que actúa sobre la autoestima de su población y la elimina de la imaginación turística del estado más visitado de Brasil. A partir de 2017, se han desarrollado acciones de política pública para cambiar la connotación de este territorio, centrándose en la riqueza natural presente allí. Este artículo buscó discutir la importancia del intercambio de conocimiento entre la Academia y la Sociedad en el área de Turismo y Ocio, a través de la experiencia del 'Observatorio de Turismo y Ocio de la Región de Turismo de Baixada Verde', con sede en UFRRJ, creado a partir de Este nuevo contexto regional. De carácter descriptivo y cualitativo, utilizó la investigación documental y bibliográfica y el informe de la experiencia. Como resultado, en dos años de actividad del Observatorio, el inventario de la oferta turística de seis municipios, la actualización del inventario de un municipio y 
las encuestas a los residentes ya permiten análisis y consideraciones, y una repercusión positiva del trabajo que se realiza, teniendo como basado en la nueva imagen que se construirá para la región.

Palabras clave: Desarrollo del turismo regional, Baixada Fluminense, Baixada Verde, Observatorio de turismo, Estado del Rio de Janeiro.

\section{Abstract:}

Historically, the Baixada Fluminense, located in the metropolitan region of the state of Rio de Janeiro, is known for its politicalterritorial segregation, which acts on the self-esteem of its population and removes it from the tourist image of the most visited state of Brazil. From 2017, public policy actions have been developing to change the connotation of this territory, focusing on the natural wealth present there. This article aimed to discuss the importance of knowledge exchange between the Academy and Society in the area of Tourism and Leisure, based on the experience of the 'Tourism and Leisure Observatory of the Baixada Verde Tourism Region', based in UFRRJ, created from this new regional context. Of a descriptive and qualitative nature, it used the documentary and bibliographical research and the experience report. As a result, in two years of the Observatory's activity, the inventory of the tourist offer of six municipalities, the updating of the inventory of a municipality and surveys with residents already allow analysis and considerations, and positive repercussion of the work being done, having as based on the new image to be built for the region.

KEYWORDs: Regional Tourism Development, Baixada Fluminense, Baixada Verde, Tourism Observatory, Rio de Janeiro State.

\section{INTRODUÇÃO}

Este artigo tem como objetivo geral refletir sobre a importância do intercâmbio de conhecimento entre a Universidade e a Sociedade na área do Turismo e do Lazer a partir das análises das atividades de extensão universitária realizadas pela equipe do Observatório de Turismo e Lazer da Baixada Verde, sediado na Universidade Federa Rural do Rio de Janeiro (UFRRJ). Para tanto, faz-se necessário a discussão de temas relacionados à importância das ações da extensão universitária; estratégias de mobilização social em prol do planejamento do turismo na Baixada Fluminense, bem como os desafios que envolvem a sensibilização política para o fomento da atividade turística em um território que, apesar de possuir potencial turístico, apresenta problemas graves de infraestrutura e serviços.

Isto porque, a região localizada na Região Metropolitana do Rio de Janeiro (RMRJ), configura-se como uma realidade socioespacial em que se condensam as dramáticas contradições vivenciadas pela sociedade brasileira. Enne (2004, p. 14), ao analisar o processo de produção de representações sociais sobre a Baixada Fluminense, tendo como referência o material produzido pela imprensa carioca da década de 1950 até o ano 2000, identificou que a imagem da região passou a ser associada plenamente com as imagens de "terra sem lei", "maior violência do mundo", "terra em que até galinha cisca pra trás", "faroeste fluminense", dentre outras classificações negativas.

Em 2018, o Atlas da Violência produzido pelo Instituto de Pesquisa Econômica Aplicada (IPEA) e pelo Fórum Brasileiro de Segurança Pública, indicou o município de Queimados como o mais violento do país. Segundo aquela pesquisa, a cidade tem taxa de 134,9 mortes violentas para cada 100 mil habitantes. Já o município de Japeri é o lugar com o pior Índice de Desenvolvimento Humano (IDH) do Rio de Janeiro, conforme divulgado pelas Nações Unidas pelo Desenvolvimento (PNUD) e pelo Instituto de Pesquisa Econômica Aplicada (IPEA), em 2018. Duque de Caxias, apesar dos indicadores positivos no que tange à economia, em 2010 ocupava a $1574^{a}$ posição entre 5.565 municípios brasileiros no ranking do Índice de Desenvolvimento Humano-Municipal (IDH-M), segundo Raulino (2013), ou seja, ao redor da maior refinaria de petróleo do país, está também uma das áreas mais miseráveis do estado.

Diante deste contexto, de graves problemas urbanos e pobreza acentuada, o incentivo ao desenvolvimento do setor de turismo nunca foi prioridade, tanto para as prefeituras locais quanto para Secretaria de Turismo do Estado do Rio de Janeiro (SETUR). À primeira vista, pode parecer contraditório o investimento no fomento ao turismo em um território com tantas precariedades, mas é preciso ressaltar que ao estruturar uma 
cidade com infraestrutura e serviços para receber um fluxo de turismo, a população local também se beneficia destas melhorias urbanas, seja através da geração de emprego e renda, seja com a elevação da auto estima por morar em uma cidade que oferece qualidade de vida e opções de lazer.

Outro ponto que merece destaque ao descrever a Baixada Fluminense, é a relação de dependência econômica que a Baixada Fluminense possui com a capital fluminense. No que tange à atividade turística, algumas observações podem ser feitas. A cidade de Rio de Janeiro (RJ) é importante centro receptor de turistas nacionais e estrangeiros. Vale aqui citar que o ano de 2016 fechou um ciclo de importantes investimentos/ megaeventos realizados na capital fluminense, sendo o último deles a realização dos Jogos Olímpicos de Verão 2016 e dos Jogos Paraolímpicos 2016. À época, uma grande expectativa foi criada com relação aos legados que tais investimentos deixariam, um deles seria a promoção da cidade do Rio de Janeiro (e municípios do entorno) enquanto destino turístico consolidado para visitação. Contudo, nem mesmo durante a realização dos megaeventos foi observado aumento do fluxo turístico na Baixada Fluminense. Sendo assim, este episódio relatado é um exemplo de como os municípios da RMRJ (com exceção de Niterói) são praticamente ignorados e desconhecidos dos turistas, além da falta de vontade política para promover a Baixada Fluminense enquanto destino de lazer e turismo.

Em que pese o estigma de "região pobre e violenta" que a Baixada Fluminense possui, além de ser um território densamente populoso e povoado[1], há ali potenciais atrativos turísticos que precisam ser "lapidados" para o usufruto de turistas e moradores. É justamente sobre o processo de planejamento turístico, iniciado em 2017, que tem o intuito de planejar e divulgar os atrativos turísticos presentes na vertente oeste da RMRJ, que este texto se propõe a refletir.

$\mathrm{O}$ artigo apresentado se caracteriza como descritivo de caráter qualitativo. Vale-se da pesquisa documental e bibliográfica, bem como das técnicas de observação participante e do relato de experiências das atividades desenvolvidas nos anos de 2017,2018 e primeiro semestre de 2019 pelo Observatório de Turismo e Lazer da Baixada Verde, criado pela UFRRJ, como uma parceria, no intuito de apoiar esse novo contexto de política de desenvolvimento do turismo na região. Assim, as principais experiências foram: i) a participação ativa nas reuniões do Fórum Regional de Turismo da Baixada Verde; ii) participação, representando a Universidade, nos Conselhos Municipais de Turismo consolidados (ou em fase de estruturação) das prefeituras municipais; iii) trabalhos de campo para a coleta de dados in loco dos Inventários da Oferta Turística. Estas ações proporcionaram a observação direta da realidade política, institucional, estrutural de cada município; do envolvimento do poder público, iniciativa privada e comunidade em geral; bem como possibilitou avaliar o envolvimento dos alunos da Universidade em uma atividade prática na região onde a Universidade está implantada, sejam estes moradores ou não da Baixada Fluminense, levando-nos à reflexão sobre o papel da Academia junto à Sociedade e ao enfrentamento das desigualdades sociais e territoriais.

No primeiro tópico deste artigo, é feito um resgate analítico da experiência recente de mobilização social em prol do fomento à atividade turística na Baixada Fluminense. Em seguida, é discutido o papel das atividades de extensão universitária e a experiência do Observatório de Turismo e Lazer da Baixada Verde. Por fim, é realizada uma análise das características regionais e alguns resultados do projeto.

\section{A MOBILIZAÇÃo INICIAL PARA o DESENVOLVIMENTO TURístico REgionaL}

Para refletir sobre políticas públicas na área de turismo, é preciso ponderar que, segundo as orientações de política pública em nível federal, o país é dividido em regiões turísticas. O mapeamento das Regióes Turísticas tem por objetivo a organização territorial e a gestão da atividade, constituindo instâncias intermediárias de articulação entre o estado e os municípios. Como resultado, o estado do Rio de Janeiro é dividido em 12 regiões turísticas - uma delas é a 'região turística Baixada Fluminense', com pouco protagonismo no cenário estadual. 
Fato é que a SETUR tem priorizado investimentos nas regiões consideradas estratégicas para o Turismo no estado: as regiões turísticas Metropolitana (referente à capital, Rio de Janeiro e Niterói); Costa Verde; Costa do Sol (Polo Litoral); Serra Verde Imperial; Vale do Café; e, Agulhas Negras (Polo Serra), como pode se observar quanto aos investimentos do Programa Nacional de Desenvolvimento do Turismo (PRODETUR[2]) e o projeto de Inventariação da Oferta Turística (IOT) que contemplou municípios destas regióes entre 2015 e 2017.

Mesmo diante de um cenário pouco animador - falta de investimentos econômicos e inércia no que tange às políticas públicas de turismo - no início do ano de 2017 , encontrava-se em processo de amadurecimento uma série de articulações entre representantes de secretarias municipais, empresários e entidades de classe ligadas, de forma direta ou indireta, ao Turismo dos 10 municípios[3] que compunham a então 'região turística Baixada Fluminense'. Este grupo tinha como objetivo a definição de estratégias para o desenvolvimento do setor na região e convencimento de instâncias superiores do potencial turístico da Baixada. O processo de mobilização regional, iniciado em 2017, amadureceu e os seus participantes criaram o Fórum de Turismo da Baixada Verde.

Foi durante a segunda reunião do grupo, que aconteceu no final do primeiro semestre de 2017, cuja pauta principal tratava da articulação da criação do Fórum, que a Universidade Federal Rural do Rio de Janeiro (UFRRJ) se fez presente no processo. Representada por professores e alunos do curso de Turismo (ofertado no Campus de Nova Iguaçu) recebeu convite para participar no intuito de contribuir com o intercâmbio de conhecimento entre academia e sociedade. Durante as discussóes sobre as demandas iniciais do grupo que compóe o Fórum de Turismo da Baixada Verde, surgiu a necessidade de levantamentos de dados que embasassem a tomada de decisões quanto ao desenvolvimento de políticas públicas para o Turismo, tanto municipais quanto regionais. A formação de um grupo de pesquisa que levantasse dados necessários à temática foi a primeira demanda que o Fórum apresentou à UFRRJ.

Uma das primeiras ações deste grupo foi deliberar pela mudança de nome da região turística de Baixada Fluminense para Baixada Verde; uma aposta discursiva para reverter a imagem negativa associada à Baixada Fluminense, lançando mão de uma inegável riqueza natural presente neste território[4]. Assim, acreditou-se que a mudança de nome seria benéfica para destacar as qualidades da região e buscaria desviar a atenção do estigma de degradação socioespacial, desordem urbana, violência e pobreza que afasta o turista e gera baixa estima nos moradores.

O intuito de mudança de imagem regional é destacado no Plano Estratégico da Região Turística Baixada Verde, lançado em fevereiro de 2018, ao evidenciar que "a mais recente denominação de Baixada Verde gerou maior visibilidade e oportunidade de posicionar o local no cenário do turismo regional de forma renovada" (Sebrae/RJ, 2018, p. 11), validando a perspectiva ao apresentar que "contribuirá para impulsionar o Turismo local uma vez que lhe dará nova conotação ao nos referirmos à Baixada Fluminense, remetendo à natureza e ao ecoturismo, proporcionando uma visão mais positiva e adequada ao potencial turístico da região" (Sebrae/RJ, 2018, p. 11). A partir de então, a região se insere oficialmente em estratégicas políticaorganizacionais para o Turismo, tendo o setor como uma alternativa capaz de fomentar o desenvolvimento regional.

Convém ressaltar, que tanto o estabelecimento do Fórum quanto a criação da Região Turística Baixada Verde estão alinhados com a principal política pública nacional, o Programa de Regionalização do Turismo - Roteiros do Brasil (PRT), lançado em abril de 2004[5].

Retomando o papel da Universidade na sociedade, ao aceitar este desafio, apresentado no final do ano 2017, e dentro da perspectiva do Plano Nacional de Turismo 2018-2022 (MTur, 2018; Brasil, 2019) - que prevê a criação de Observatórios do Turismo por meio da parceria das regiões turísticas com Universidades - um grupo de professores do curso de Turismos se uniu para criar um Observatório de Turismo e submeter um projeto ao edital do Programa de Bolsa Institucionais de Extensão (BIEXT) 2017[6], da UFRRJ (contemplado com uma bolsista de extensão para atuação no ano de 2018). Após discutir as características 
e necessidades da região, a equipe do Observatório decidiu acrescentar a perspectiva do Lazer ao projeto, definindo que seria criado então um Observatório de Turismo e Lazer para a região turística da Baixada Verde.

Ao inserir as questões relativas ao lazer, pretende-se destacar que as ações do Observatório visam tanto fomentar o aumento do fluxo turístico (e assim diversificar as atividades econômicas regionais), quanto qualificar esta região como um espaço de lazer para os moradores da Baixada, gerando mais qualidade de vida e elevação da autoestima da população local.

\section{O PAPEL DA EXTENSÃO UNIVERSITÁRIA E O INTERCÂMBIO DE CONHECIMENTOS NA ÁREA DO TURISMO}

A Universidade tem suas atividades fundadas em três pilares: o Ensino, a Pesquisa e a Extensão. Estes pilares não devem ser desenvolvidos de forma unilateral, muito pelo contrário, todos devem se correlacionar e fortalecer um ao outro. Nesse sentido, o Ensino, principal eixo de atuação da Universidade, não pode ficar alheio à Pesquisa que o alimenta e o atualiza constantemente. Tampouco este pode deixar de se relacionar com a Extensão, uma vez que, segundo a Resolução no 7, de 18 de dezembro de 2018 (Brasil, 2018), que estabelece as Diretrizes para a Extensão na Educação Superior Brasileira.

A Extensão na Educação Superior Brasileira é a atividade que se integra à matriz curricular e à organização da pesquisa, constituindo-se em processo interdisciplinar, político educacional, cultural, científico, tecnológico, que promove a interação transformadora entre as instituições de ensino superior e os outros setores da sociedade, por meio da produção e da aplicação do conhecimento, em articulação permanente com o ensino e a pesquisa. (Brasil, 2018, p.1-2).

Assim, na Pesquisa também é importante levar em consideração as demandas da sociedade, no intuito de atender suas necessidades, gerando dados que a ajudem a resolver os seus problemas e desenvolver estratégias para melhoria de suas vidas, o que articula Pesquisa e Extensão, como afirma Fogaça (2016, p.75)

Por meio da extensão universitária a Universidade difunde seu conhecimento junto à sociedade, incentivando o empoderamento da mesma sobre os rumos de suas vidas e da coletividade, e, por outro lado, realimenta-se por meio da troca de conhecimento e aprimora o ensino e a pesquisa.

Portanto, a Extensão Universitária, em uma concepção mais contemporânea, vai além da disseminação de conhecimento, prestação de serviços e difusão cultural, mas significa oxigenação à vida acadêmica. Assim, segundo Fogaça (2016, p.76-77)

a partir dessa nova concepção, a extensão deixa de ser um acessório da Universidade além do ensino e da pesquisa, e tornase uma de suas missões, parte indispensável do pensar universitário, em que a extensão é vista como um instrumento para a formação de um profissional cidadão por meio da interação dos estudantes com a sociedade.

No sentido da interação entre a Universidade e a Sociedade, estão os Observatórios. No caso do Turismo, o Plano Nacional de Turismo (2018-2022) (MTur, 2018, Brasil, 2019 - Decreto ${ }^{\circ}$ 9.791, de 14 de maio de 2019), como já destacado, prevê a criação dos observatórios de Turismo, para ampliar e aprimorar estudos e pesquisa do setor. De acordo com o documento citado

Um observatório de turismo tem entre os seus objetivos o acompanhamento, observação, coleta, tratamento, análise, geração e monitoramento de dados e informações sistemáticas e padronizadas sobre atividade turística em distintos níveis administrativos regional, estadual e municipal [...] sua principal atividade relaciona-se, geralmente, com a estruturação e manutenção de bancos de dados que permitem a mensuração e análise da atividade turística sistemática e regular (MTur, 2018, p.83).

O intuito do Ministério do Turismo (2018, p.84) “[...] é estabelecer uma rede de observatórios de Turismo para propiciar o intercâmbio de dados, estudos e estatísticas e subsidiar a implantação, a avaliação e o aprimoramento perene da Política Nacional de Turismo". Tal iniciativa pode ser gerida por organismos 
oficiais de Turismo ou vincular-se a Universidades ou associações empresariais, apresentando composição e estruturas funcionais diversificadas (MTUR, 2018). No caso das parcerias com Universidade, isso se dá por meio de Acordos de Cooperação Técnica entre as regiões turísticas e as Universidades para elaboração de inventários, pesquisas de demanda, pesquisa junto à população, entre outras, ações contempladas tanto no que tange à Pesquisa quanto à Extensão. Ademais, com a Resolução no 7/2018 (Brasil, 2018), que estabelece que $10 \%$ do currículo dos cursos de graduação devem se relacionar com a Extensão, essa relação fica ainda mais intrínseca.

No Brasil, há inúmeros observatórios de Turismo, especialmente geridos por órgãos governamentais, mas, especificamente, no âmbito acadêmico, podemos citar o observatório do Turismo no Rio de Janeiro, da Universidade Federal Fluminense (UFF). Segundo o portal do Observatório do Turismo da UFF do Estado do Rio de Janeiro (2019)

O objetivo principal do Observatório é o monitoramento do turismo no Estado do Rio de Janeiro através da produção e divulgação regular de informações e indicadores estatísticos do turismo, além da avaliação dos impactos econômicos dos grandes eventos sobre a cadeia produtiva do turismo. As pesquisas, estatísticas, indicadores e estudos produzidos pelo Observatório são importantes na orientação das políticas e planejamento do turismo nos municípios do Rio de Janeiro, no intuito de maximizar os benefícios econômicos e sociais da atividade turística e de minimizar os seus impactos negativos.

Assim, o Observatório do Turismo do Estado do Rio de Janeiro, da UFF, vem desenvolvendo pesquisas sobre o perfil do turista que visita o Rio de Janeiro, especialmente, em eventos como foi na Jornada Mundial da Juventude, Copa das Confederações, Copa do Mundo, entre outros; impactos econômicos dos eventos para a cidade do Rio de Janeiro e Niterói; bem como pesquisas sobre o perfil dos colaboradores no setor de hospedagem e sobre a evolução da ocupação destes estabelecimentos; entre outras, correlacionando o Ensino, a Pesquisa e a Extensão.

Ainda no âmbito de Universidade, existe o Observatório de Turismo do Paraná (OBSTURPR), criado pelo curso de Turismo da Universidade Federal do Paraná, em 2002, com o intuito de "Facilitar a gestão pública e privada do turismo de forma sustentável, fornecendo dados e incentivando a utilização dos mesmos" ( OBSTURPR, 2019). De acordo com o Portal do OBSTURPR as áreas de pesquisa em que atua são Alimentos e Bebidas; Agenciamento; Hotelaria; Lazer e Recreação; Planejamento em Áreas Naturais; Planejamento em Áreas Urbanas; Transportes; outras áreas, o que demonstra a relação interdisciplinar na formação dos cursos de Turismo.

É importante o envolvimento das Universidades junto aos Observatórios do Turismo, uma vez que como afirmam Pena \& Moesch $(2015$, p.6)

Os Observatórios devem ter a preocupação com a transposição da produção científica a ser construída para as políticas públicas, para o mercado, na busca da sustentabilidade do Turismo das diferentes regiões. Assim, com o objetivo de promover a análise, divulgação e o acompanhamento da evolução do Turismo nacional, de forma independente e responsável, garantindo a objetividade da sua produção técnico-científica, de modo a contribuir para o desenvolvimento de um Turismo sustentável no território nacional integrado nas estratégias globais de desenvolvimento regional.

Os autores ainda apontam que o debate sobre a produção do conhecimento científico de um Observatório de Turismo tem relevância social para o desenvolvimento do Turismo regional, e se justifica se estes forem estruturados a partir dos eixos:

a) promoção da integração entre Instituições de Ensino Superior, setores produtivos do turismo e institutos de pesquisa contribuindo para o desenvolvimento de pesquisas em turismo, apoiando e incentivando projetos de pesquisa e extensão universitária; b) suporte a grupos de pesquisas já existentes; c) Inserção nas redes de pesquisa, instâncias de governança e redes de cooperação da sua região; d) Divulgação e disseminação do conhecimento acerca da atividade turística; e) contribuição para geração e melhoria de produtos e serviços turísticos através de Pesquisa \& Desenvolvimento; f) desenvolvimento de Tecnologias Sociais aplicadas aos serviços turísticos; g) contribuição para elaboração de projetos consistentes que facilitem a captação de recursos na área da pesquisa em turismo (Pena \& Moesch, 2015, p.8). 
Ou seja, eixos que colocam em destaque a presença de Instituições de Ensino Superior nestes observatórios e relevância de suas pesquisas.

Oliveira, Miranda \& Amaral (2016, p.4), também, ao discutir o papel dos observatórios de turismo no Brasil para a tomada de decisão do setor público, destacam a importância da informação para a definição de políticas públicas, afirmando que uma vez que a gestão da informação é essencial para tomada de decisões, necessita-se ter na área de turismo uma entidade que organize, filtre e fomente a produção de informações para serem a base da formatação de políticas públicas, sendo um observatório do Turismo, uma ferramenta de inteligência no setor.

Logo, a presença de um Observatório favorece o desenvolvimento do Turismo em uma determinada região, pois como ponderam os autores:

Apesar de cada observatório apresentar estruturas organizacionais e operacionais diferentes, o objetivo de sua existência é mantido a fim de manter a competitividade do destino, produzindo e manuseando informações que podem ser úteis para os processos internos da instituição que o incorpora e também para a comunidade, uma vez que se as informações subsidiadas pelo mesmo forem base para o processo de tomada de decisões e formatação de políticas de turismo, sempre se adequando às necessidades e à realidade de cada território (Oliveira, Miranda \& Amaral, 2016, p.17).

Desta forma, ao pensar no desenvolvimento do Turismo na Baixada Verde e na relação UniversidadeSociedade diante de um contexto socioeconômico presente na região, a criação do Observatório de Turismo e Lazer da Região Turística da Baixada Verde, é um dos grandes pilares e, mesmo, esperança para se alcançar o desenvolvimento do Turismo regional e impulsionar a melhoria na qualidade de vida de sua população. Para os alunos, está a perspectiva de uma formação cidadã e da contribuição com a região que habitam, geração de emprego e renda no setor, bem como, a construção de um campo de atuação profissional próximo ao local de sua residência, antes algo inimaginável já que a maior parte dos estágios disponíveis se concentram na capital fluminense.

\subsection{Ações do Observatório do Turismo e Lazer da Região Turística Baixada Verde}

Diante do contexto descrito, o Observatório de Turismo e Lazer da Região Turística Baixada Verde, desde 2017 vem contribuindo para o fomento do Turismo regional através de ações de assessoria ao Fórum e municípios da Baixada Verde, geração de dados e participação na avaliação, no monitoramento e na divulgação das políticas públicas de Turismo da Baixada Fluminense.

Mesmo antes da institucionalização do Observatório, no primeiro semestre de 2017, parte dos docentes do curso de Turismo, bem como discentes, participavam como membros titulares do Conselho Municipal de Turismo de Nova Iguaçu (COMTUR-NI) e como colaboradores do Fórum Regional de Turismo da Baixada Verde.

Ainda em 2017, os professores que criaram o projeto do Observatório, simultaneamente a esta tarefa, participaram da elaboração do "Plano Estratégico da Região Turística - Baixada Verde”, coordenada pelo Serviço de Apoio às Micro e Pequenas Empresas no Estado do Rio de Janeiro (Sebrae/Rio de Janeiro, 2017) e lançado em fevereiro de 2018.

$\mathrm{Na}$ apresentação do documento, destacam-se a possibilidade de inserção da Baixada Fluminense no contexto do Turismo regional e nacional tendo o novo título Baixada Verde como elemento importante. O papel da UFRRJ foi ressaltado no documento Plano Estratégico, definido em cinco eixos estratégicos (Infraestrutura; Qualificação; Mercado; Políticas Públicas; Gestão e Monitoramento). No eixo Gestão e Monitoramento estava prevista a implantação do Observatório de Turismo e Lazer da UFRRJ e, no eixo Infraestrutura, a elaboração do inventário da oferta turística de cada um dos municípios, em curto prazo.

Com a criação e institucionalização do Observatório, definiu-se que sua primeira ação seria realizar os inventários turísticos dos dez municípios da região. Nos municípios de Seropédica e Nova Iguaçu, no âmbito 
da disciplina de Planejamento e Organização de Turismo, lecionada aos alunos de Turismo da UFRRJ, já havia sido realizado um inventário, respectivamente em 2011 e em 2012. Logo, a demanda se relacionava à atualização do material que já tinha sido elaborado e adequação à metodologia definida pelo Ministério do Turismo, no âmbito do programa Inventário da Oferta Turística (INVTUR). O município de Duque de Caxias, também já tinha o seu inventário feito por uma empresa privada, o Instituto Ideias, em 2011, então para esse município o trabalho também seria de atualização.

Assim, em 2018, o Observatório de Turismo e Lazer da Baixada Verde, diante do apoio conseguido pelos Programas de Bolsas de Pesquisa e Extensão da UFRRJ, do empenho de professores e alunos que o compõem, bem como apoio das secretarias de Turismo de alguns dos municípios da Baixada Fluminense, conseguiu realizar os inventários da oferta turística dos municípios de Magé, Japeri, Nilópolis e Mesquita, bem como atualizar o inventário de Nova Iguaçu. A ilustração a seguir traz a imagem divulgada por um portal do município de Magé/RJ, da equipe que realizou o trabalho no município, no primeiro semestre de 2018.

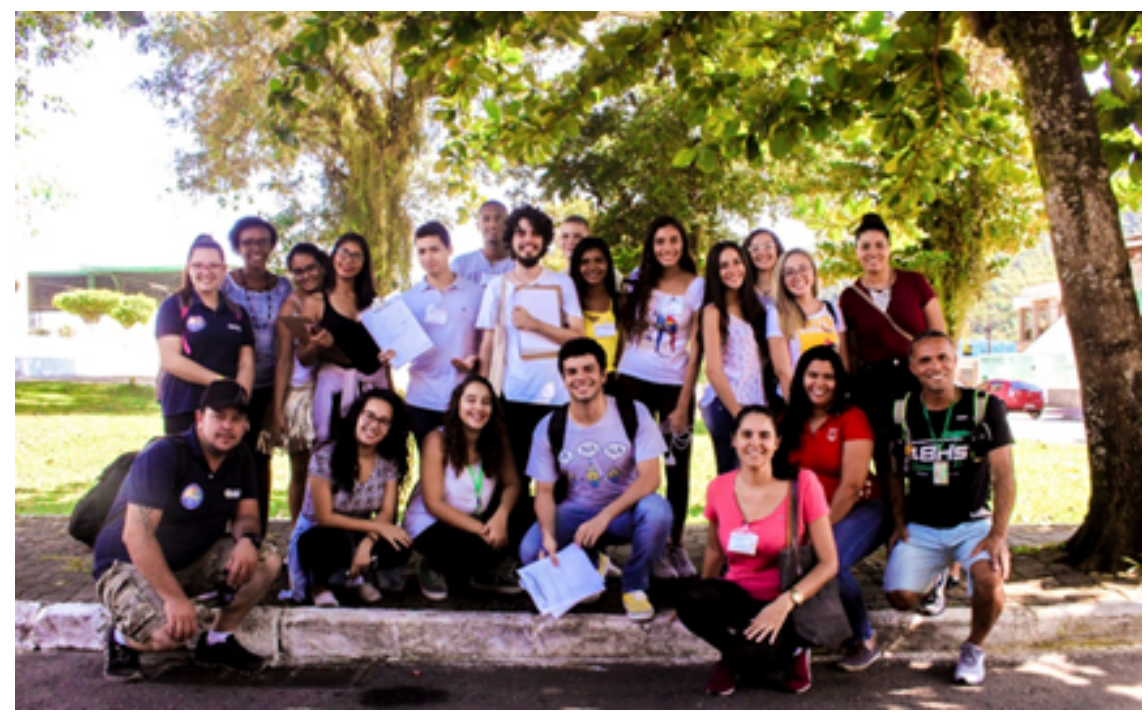

Figura 1. Baixada Verde - Magé e UFRRJ catalogam pontos turísticos Canal Magé, 2018

Neste mesmo ano, além da participação nas reuniões mensais do Fórum Regional de Turismo da Baixada Verde e do Conselho Municipal de Turismo de Nova Iguaçu (COMTUR-NI), membros do Observatório contribuíram assessorando na construção de um regimento que transformou o antigo formato institucional Fórum de Turismo da Baixada Verde em Conselho Regional de Turismo da Baixada Verde, pois esse formato de instância de governança regional estaria mais adequado às orientações do MTur - sobretudo com relação à previsão de um Fundo Regional para o Turismo.

Em 2019, foram iniciados os inventários da oferta turística dos municípios de Queimados e São João de Meriti. Faltando apenas a atualização dos inventários de Duque de Caxias e Seropédica, bem como a realização do inventário da oferta turística do município de Belfort Roxo, o que se pretende alcançar no segundo semestre de 2019 e primeiro de 2020.

Ainda em 2019, foram iniciadas outras frentes de pesquisa que visam auxiliar na tomada de decisão sobre o planejamento do Turismo e do Lazer na região, através de projetos de pesquisa aprovados junto ao Programa de Iniciação Científica da Fundação de Apoio à Pesquisa do Estado do Rio de Janeiro (FAPERJ) como: a) pesquisa de opinião pública junto à comunidade para levantar seus anseios e receios sobre o desenvolvimento do Turismo em cada município, bem como sobre a realidade dos espaços de lazer e demandas da população quanto a essa temática; b) levantamento das iniciativas de economia solidária e criativas e discussão de formas destes grupos se integrarem ao conjunto macroeconômico já existente na região e contribuírem com o desenvolvimento do Turismo; c) definição de indicadores de avaliação e de competitividade dos 
municípios da região que servirá à etapa subsequente à elaboração dos inventários da oferta turística da região, o diagnóstico.

Também junto ao Programa de Institucional de Bolsas de Iniciação Científica (PIBIC) financiado pelo Conselho Nacional de Desenvolvimento Científico e Tecnológico (CNPq) e pela UFRRJ foram aprovadas pesquisa para: a) catalogação das áreas naturais preservadas, muitas delas unidades de conservação legalmente instituídas, mas poucas implantadas e diagnóstico das condições de implantação das mesmas; e, b) mapeamento da estrutura organizacional e política do Turismo na região, especialmente quanto à infraestrutura básica e de apoio ao Turismo, bem como da superestrutura, ou seja, da complexa organização política pública e privada de gestão do Turismo.

Além das pesquisas já aprovadas em programas de apoio à pesquisa, foi realizado um levantamento de demandas de pesquisas e/ou ações de extensão, cujos projetos estão em elaboração. Entre as pesquisas e/ou ações de extensão necessárias estão:

i) Investigação das condições dos recursos hídricos da região e as possibilidades de sua recuperação para uso econômico e de recreação;

ii) elaboração de mapas de orientação turística;

iii) análise sobre o Marketing Verde e sua contribuição para a mudança de imagem da região;

iv) inventário do patrimônio cultural edificado e imaterial presente na região (quanto ao imaterial: levantamento de grupos de quadrilhas juninas; agremiações e blocos carnavalescos, cordelistas, terreiros, entre outros)

v) debate sobre o uso do patrimônio cultural da região para a melhoria da autoestima da população e reconhecimento de sua importância no contexto estadual e, até nacional, além da promoção socioeconômica; entre outras.

Com as pesquisas aprovadas e as propostas, somaram-se ao grupo de professores de Turismo, professores do curso de Administração e Geografia da UFRRJ, campus Nova Iguaçu, da Faculdade de Administração e Finanças da Universidade do Estado do Rio de Janeiro (UERJ) e do Programa de Pós-graduação em Psicossociologia de Comunidades e Ecologia Social (Eicos) da Universidade Federal do Rio de Janeiro (UFRJ) e do Programa de Pós Graduação em Políticas Públicas, Estratégias e Desenvolvimento da mesma Universidade, tendo sido o projeto contemplado, na faixa $A$ de fomento, no edital de apoio às instituições de Ensino Superior sediadas no Estado do Rio de Janeiro pela FAPERJ.

Assim, tais ações, além de gerar dados para a tomada de decisão da instância regional de Turismo, o Conselho de Turismo da Região Baixada Verde visam fortalecer a pesquisa realizadas no âmbito do curso de Turismo, Administração e Geografia (UFRRJ e UERJ), bem como dos programas de Pós Graduação que contam com a participação de alguns dos professores que compõem o Observatório, como o Programa de Pós Graduação em Patrimônio, Cultura e Sociedade; Programa de Pós Graduação em Geografia; Programa de Pós Graduação em Administração; Programa de Pós Graduação em Práticas em desenvolvimento Sustentável da UFRRJ; e Pós-graduação em Ecoturismo e Conservação (UNIRIO); bem como os já citados do Programa de Pós-graduação em Psicossociologia de Comunidades e Ecologia Social/ EICOS e Programa de Pós Graduação em Políticas Públicas, Estratégias e Desenvolvimento da UFRJ. Isto destaca o caráter multidisciplinar e interinstitucional do Observatório de Turismo e Lazer da Região Turística Baixada Verde.

As ações do Observatório realizadas em 2018 e no primeiro semestre de 2019, têm sido divulgadas nos meios de comunicação de cada município e na imprensa do estado do Rio de Janeiro, proporcionando revelar a Baixada Verde não mais como o lugar da miséria e da violência. Durante busca na web com a denominação Baixada Verde é revelada ao público uma nova imagem da região, ligada às áreas naturais, de lazer e ao patrimônio histórico dos municípios. Nestas pesquisas, é possível descobrir que a região concentra, aproximadamente, um terço da cobertura vegetal ainda presente no estado, em maior parte referente ao Bioma Mata Atlântica. São extensas áreas naturais preservadas, muitas delas Unidades de Conservação legalmente instituídas nas diversas categorias estabelecidas pelo Sistema Nacional de Unidade 
de Conservação (SNUC) e recursos hídricos, importantes para o abastecimento do estado, como a Reserva Biológica Tinguá (REBIO Tinguá), em Nova Iguaçu, e Área de Proteção Ambiental (APA) Guandu (Japeri, Nova Iguaçu, Queimados e Seropédica), cujo rio que nomeia a APA é responsável pelo abastecimento de milhões de habitantes de municípios do Estado e da capital.

Destaca-se ainda a APA de Guapi-Mirim (Magé) e a localização de Magé em um vale formado pela base da Serra dos Órgãos, uma cordilheira do estado do Rio de Janeiro onde estão situados o Parque Nacional da Serra dos Órgãos e o Parque Estadual dos Três Picos, com forte potencial turístico; o Parque Municipal de Nova Iguaçu (PMNI); o Parque Municipal de Gericinó (Mesquita e Nilópolis); e, a APA Pico da Coragem (Japeri), cuja imagem a seguir ilustra a discussão; entre outros.

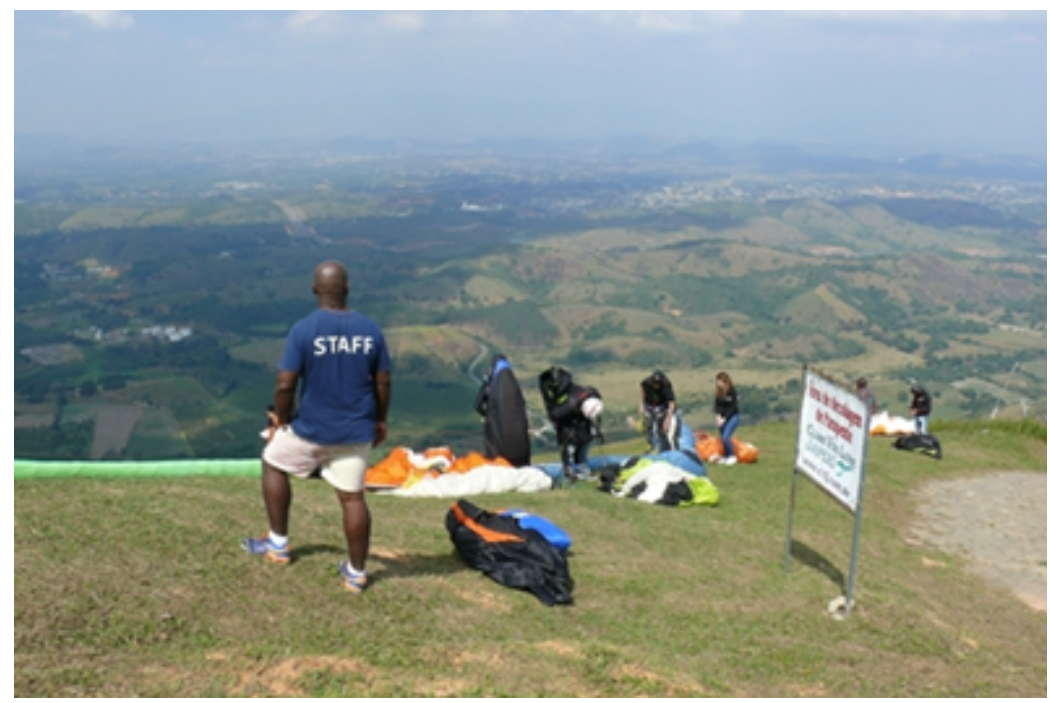

Figura 2. Pico da Coragem (Japeri)

Jornal de Hoje, 10/novembro/2017

Além do potencial em recursos naturais, a região ainda conta com um rico patrimônio cultural e histórico que tem como ícone a Fazenda São Bento onde está instalado o Museu Vivo de São Bento (Duque de Caxias); as ruínas da Fazenda São Bernardino (Nova Iguaçu) e a Estação de Trem de Guia de Pacobaíba (Magé), primeira estação ferroviária do Brasil, igrejas centenárias, entre outros. Assim como, o patrimônio imaterial revela a história e a vida do povo da Baixada, destacam-se as agremiaçóes carnavalescas como as Escolas de Samba Beija Flor de Nilópolis, a Grande Rio (Duque de Caxias), entre outras; centenas de locais de manifestações de fé como terreiros que retratam religiões de matriz africana; grupos de folias de reis e de quadrilha de festa junina, extremamente marcantes na cultura da população da Baixada Fluminense. Destacam-se, também, locais de celebração à música, à dança, à literatura e à rica gastronomia nordestina, população imigrante de grande participação na construção histórica e territorial da região.

\subsection{Desafios para o desenvolvimento do Turismo na região da Baixada Verde}

Apesar da vontade e empenho de gestores públicos, docentes e estudante envolvidos com o Observatório de Turismo e Lazer da Região Turística Baixada Verde, inúmeros são os desafios para o desenvolvimento tanto do Turismo na região quanto para a realização do trabalho a que se propõe o Observatório.

O quadro de insegurança e violência vivido nos municípios abrangidos pelo projeto e contemplados nas ações do Observatório, já tratado anteriormente, é destacado como um dos maiores obstáculos. Machado (2012; 2013) sobre 'Turismo e medo social' caracteriza essa realidade como “[...] o medo construído socialmente e que afeta a coletividade" (Machado, 2012, p.49). Citando Baierl (2001, p.20 apud Machado, 2012, p.49), o autor complementa afirmando que "[...] isso se a agrava pela forma corriqueira do crime e, 
principalmente, pela ineficiência e impunidade no papel da polícia e do Estado frente à questão social”. Assim, Machado (2012; 2013) argumenta que o medo social que vem alterando o território e o tecido urbano de muitas cidades brasileiras e a vida das suas populações afeta o Turismo, uma vez que "o temor em vivenciar experiências indesejadas é relevante fator limitante na escolha de um destino turístico” (Machado, 2012, p. 48).

Todavia, não só turistas temem vir à região ou acessar algumas áreas com potencial turístico, com destaque para as áreas com riqueza natural ou valor cultural. Para a execução das atividades propostas pelo Observatório, especialmente os inventários, alunos, professores e mesmo gestores públicos se sentem acuados e com medo de acessar algumas áreas em que grupos criminosos, como traficantes e milicianos, controlam o território. Durante o levantamento de campo no município de Mesquita, por exemplo, funcionários da prefeitura orientaram a equipe a não usar roupas da cor vermelha por medida de segurança, pois esta cor desagradaria uma certa facção criminosa que domina parte da cidade. Inúmeros foram os casos de grupos de alunos acessarem as áreas para execução do inventário escoltados por membros das associações de moradores e/ou com o apoio e intercessão de membros do poder público, como defesa civil, secretarias de meio ambiente, secretários de outras pastas e políticos.

Outro elemento limitador é a condição da infraestrutura de acesso a estas áreas. Normalmente, os locais com potenciais turísticos não são facilmente acessíveis em automóveis de passeio, bem como não é possível acessar em transporte público, exigindo veículo especial para acessá-los, o que dificulta e limita a visitação. O mesmo ocorre com a infraestrutura de sinalização: praticamente não há sinalização de acesso às áreas com potencial (com exceção do Parque Municipal de Gericinó, em Nilópolis, e da quadra da Escola de Samba da Beija Flor, no mesmo município). Essa falta de sinalização pode colocar o visitante em perigo, ao acessar uma área por engano, em que haja risco de segurança e, atrapalhar a experiência e visitação, pois também não há sinalização de interpretação turística nestes locais, o que inclui o parque de Nilópolis. Assim, o turista que conseguir chegar na localidade não terá placas explicativas que o leve a conhecer melhor o atrativo e a aprimorar sua visitação e experiência.

Considera-se, também, como um limitador, o desconhecimento por parte de membros dos órgãos públicos de Turismo e demais correlatos (Cultura, Educação, Lazer, entre outros) sobre seus próprios municípios. O levantamento de dados para o inventário se dá, inicialmente, através de uma listagem preliminar (preparada pelos alunos em pesquisa de gabinete) dos itens a serem inventariados. Em seguida, esta listagem é enviada aos gestores para validação; no entanto, são poucas as contribuições acrescentadas aos documentos, por falta de conhecimento dos potenciais turísticos e do território, por eles. Há casos em que o secretário e funcionários não residem no município, desconhecendo os locais que podem ser trabalhados para o Turismo, ou estão atuando com mais afinco em outros temas das suas secretarias como (Cultural, Esportes, Terceira Idade, Desenvolvimento Econômico, etc.) e deixam o Turismo em segundo plano. Isso dificulta o trabalho de gabinete, bem como o trabalho de campo, pois não se consegue alcançar um bom planejamento e eficácia de campo, sendo necessário a equipe retornar inúmeras vezes ao município para a coleta de dados, o que torna o processo oneroso e longo.

Identifica-se, ainda, uma resistência dos prestadores de serviços em alguns municípios ou localidades a responderem e participar das ações do projeto (como responder aos questionamentos para o inventário). Além disto, muitos empreendedores e moradores ficam com medo da aproximação dos alunos e professores (vestidos com coletes e crachás do projeto) solicitando informações para o inventário com receio de uma fiscalização do poder público (muitas vezes, a equipe chega aos locais em carros oficiais com adesivos da prefeitura ou da UFRRJ). Há ainda aqueles que ficam surpresos com a proposta de desenvolvimento do Turismo na região, considerada por muitos como violenta, feia, degradada etc., o que impossibilita a ideia de desenvolvimento do Turismo para o lugar na visão dos moradores. Portanto, constata-se que a imagem reverberada pela mídia é validada pelos atores locais. Essa situação se repete com os moradores e mesmo, com outros agentes públicos, não envolvidos com o projeto, até do Executivo. Assim, há 
um desconhecimento generalizado dos potenciais turísticos de seus municípios e uma descrença nas possibilidades de desenvolvimento do Turismo.

Ainda no que se refere às dificuldades para o desenvolvimento do trabalho do Observatório, no que tange à Universidade, sua estrutura e apoio, nestes dois anos de atuação, foi um desafio, especialmente para a obtenção/acesso a recursos para transporte e alimentação da equipe, cópias de material impresso e aquisição de equipamentos (como tablets, computadores, coletes, software de banco de dados, etc.), entre outros, que limitam a atuação do grupo e fazem com que atividades, que poderiam ser realizadas em curto prazo e de forma dinâmica, tornem-se longas e cansativas. As prefeituras também contam com recursos escassos e problemas de dívidas com a União que impedem a captação de recursos para projetos do setor e maior apoio ao Observatório; mesmo assim há esforços para sanar as dificuldades citadas com a logística do trabalho, fornecimento de equipamentos e outros.

Outro desafio é o trabalho com alunos voluntários, sem bolsas, uma vez que são poucos os contemplados com essa ajuda de custo para as atividades. Assim, a participação nos projetos do Observatório é promovida, na maior parte das situações, por meio do argumento da aquisição de conhecimento e no significado do projeto, que tem o intuito de trazer desenvolvimento socioeconômico e socioambiental à região onde a maioria reside. Constata-se, ainda, no alunado a dificuldade de entender que o trabalho voluntário conta com responsabilidades da mesma forma que o subsidiado ou remunerado, e que essa experiência, na contemporaneidade, é de grande valor para a construção de seu currículo. Como afirma Fogaça (2016, p.98)

São poucos os órgãos de fomento à ciência e tecnologia que dispõem de editais de chamadas públicas para a seleção e financiamento à extensão, e quando comparado com a pesquisa, é sempre a 'fatia menor' que se destina à extensão, sendo a maioria dos projetos desenvolvidos na base do voluntariado.

Essa situação é (ou deveria ser) amenizada se todos os municípios da Baixada Verde oferecessem bolsas de estágio aos alunos que atuam no Observatório nas prefeituras - assim, o aluno poderia se dedicar integralmente nas atividades relacionadas ao inventário do município que concede a bolsa. Por fim, convém citar a dificuldade relacionada a inexistência de um software de banco de dados disponível para uso de forma gratuita.

Diante do cenário, são inúmeros os desafios aos que o Observatório de Turismo e Lazer da Região Turística Baixada Verde se propõe a enfrentar.

\section{Considerações Finais}

Considerando o Turismo como um importante vetor de desenvolvimento local e regional, este artigo relatou um trabalho de parceria entre Universidade e Sociedade que tem como fim alcançar um projeto de desenvolvimento turístico, que seja capaz de auxiliar na mudança do estigma de região pobre e violenta, que a Baixada Fluminense possui. Pensar Turismo no chamado "faroeste fluminense", exige uma mudança de paradigma dos pesquisadores, agentes públicos e privados envolvidos e moradores. Não estamos atuando nos chamados paraísos turísticos, buscamos destacar o que a Baixada Fluminense pode revelar para além da imagem de pobreza, degradação e violência.

Pensando na estratégia de mudança de abordagem de Baixada Fluminense versus Baixada Verde se fortalece a premissa do turismo e do lazer como ferramentas de desenvolvimento, que possibilitem dar um dinamismo econômico local e regional, levando a equalização com a preservação/conservação ambiental; a valorização da identidade cultural; a preservação de locais históricos; a qualificação de espaços para recreação e lazer dos moradores e visitantes, a melhoria nas paisagens naturais ou urbanas; além do incentivo às produções agrícolas, industriais e artesanais.

Os dados de pesquisa coletados pelo Observatório de Turismo e Lazer da Região Turística Baixada Verde, por meio do inventário da oferta turística (dados sobre projetos sociais, áreas naturais e rurais, patrimônios 
histórico-culturais materiais e imateriais, etc.), conseguem revelar os potenciais naturais e culturais da região, que indicam tanto a possibilidade de fomento à atividade econômica "Turismo", quanto, e principalmente, para o usufruto dos moradores no que tange aos espaços e práticas de lazer.

$\mathrm{Na}$ verdade, constata-se que falar de Turismo na Baixada Fluminense consiste essencialmente, como prioridade, na qualificação dos espaços de lazer e cultura para os próprios moradores da região; e no objetivo de fazer com que os moradores dos municípios de entorno, como a capital fluminense, visitem a Baixada.

Acima de tudo, é importante não deixar de mencionar que, por mais que tenha sido criada uma região turística Baixada Verde, em que as imagens propagadas na web já revelam novos olhares e perspectivas sobre a região, a atuação do projeto se dá na Baixada Fluminense. Desta forma, pensar o desenvolvimento do Turismo na Baixada Fluminense, traz as reflexões sobre 'Turismo e medo social', 'Turismo e pobreza'. Assim, destacase que o Observatório de Turismo e Lazer da Baixada Verde tem um papel muito desafiador e importante, quer seja ele o de reverter o quadro de baixa estima dos moradores da região com relação ao seu entorno, motivada pelos estigmas e imagens negativas da Baixada Fluminense, divulgadas diariamente, como revelado na pesquisa.

Busca-se, ao trabalhar no fomento do turismo regional, diante de um esforço coletivo entre Universidade, gestores públicos e diversos outros agentes sociais., melhorar a infraestrutura, serviços e atrativos, tanto para os turistas quanto para os moradores locais.

\section{REFERÊNCIAS}

Brasil. (2019). Decreto no 9.791, de 14 de maio de 2019. Aprova o Plano Nacional de Turismo 2018-2022.

Brasil. Ministério da Educação (2018). Resolução no 7, de 18 de dezembro de 2018. Estabelece as Diretrizes para a Extensão na Educação Superior Brasileira. Disponível em: < http://portal.mec.gov.br/index.php?option=com _docman\&view=download\&alias=104251-rces007-18\&category_slug=dezembro-2018-pdf\&Itemid=30192

Enne, A. L. S. (2014). Imprensa e Baixada Fluminense: múltiplas representações. Revista eletrônica Ciberlegenda. 14, 01-26. Disponível em: < http://www.ciberlegenda.uff.br/index.php/revista/article/view/222/118 > . Acessado em janeiro de 2019.

Fogaça. I. F.F. (2016). Extensão: Experiências de extensão do curso Bacharelado em Turismo da UFRRJ. In: Catramby, T. C. V. (org). Extensão: Experiências de extensão do curso Bacharelado em Turismo da UFRRJ. Curitiba: Appris, 75-100.

IBGE. Instituto Brasileiro de Geografia e Estatísticas (2010). Censo demográfico (2010). [online]. Disponível em: . Acessado em abril de 2018.

IPEA. Instituto De Pesquisa Econômica Aplicada/ Fórum Brasileiro de Segurança Pública. (2018). Atlas da Violência 2018. Disponível em: < http://www.ipea.gov.br/portal/images/stories/PDFs/ relatorio_institucional/180604_atlas_da_violencia_2018.pdf >

Machado, M. de B. T. (2012). Medo Social e Turismo no Rio de Janeiro. TMStudies [online]. 8,48-54. Disponível em: < http://www.scielo.mec.pt/scielo.php?script=sci_arttext\&pid=S2182-84582012000100006 >. Acessado em janeiro de 2019.

Machado, M. de B. T. (2103). Turismo, Medo e Violência. Turismo \& Sociedade. 6 (1), 225-228. Disponível em: < https://revistas.ufpr.br/turismo/article/view/30746 >. Acessado em janeiro de 2019.

MTur, Ministério do Turismo. (2018) Plano Nacional de Turismo: O turismo Fazendo muito mais pelo Brasil. Brasília. Disponível em: . Acessado em janeiro de 2019.

MTur, Ministério do Turismo. (2007) Secretaria Nacional de Políticas de Turismo. Departamento de Estruturação, Articulação e Ordenamento Turístico. Coordenação Geral de Regionalização. Programa de Regionalização do Turismo - Roteiros do Brasil: Introdução à Regionalização do Turismo. Brasília. 
MTur, Ministério do Turismo (2013). Secretaria Nacional de Políticas de Turismo/Departamento de Estruturação, Articulação e Ordenamento Turístico/Coordenação Geral de Regionalização. Programa de Regionalização do Turismo: Diretrizes. Ministério do Turismo. Brasília.

Observatório do Turismo do Estado do Rio de Janeiro. (2019). Niterói: Universidade Federal Fluminense. Disponível em: . Acessado em abril de 2019.

OBSTURPR, Observatório de Turismo do Paraná. (2002). Curitiba: Universidade Federal do Paraná, 2002. Disponível em: < http://www.obsturpr.ufpr.br/apresentacao.html>. Acessado em abril de 2019.

Oliveira, R. P., Miranda, I. P.\& Amaral, J. P. S. (2016). Gestão da Informação: O Papel dos Observatórios e Turismo Brasileiros para a Tomada de Decisão do Setor Público. Marketing \&Tourism Review, 1 (2), 00-31. Disponível em: < https://revistas.face.ufmg.br/index.php/mtr/article/view/3837>. Acessado em abril de 2019.

Pena, L. C. S.\& Moesch, M. (2015). A transposição do conhecimento no desenvolvimento sustentável do turismo e o papel dos Observatórios de Turismo. Anais Anptur 2015. 11.

PNUD, Programa das Nações Unidas para o Desenvolvimento. Atlas do Desenvolvimento Humano no Brasil. Disponível em: . Acessado em janeiro de 2019.

PRODETUR/RJ. Programa Nacional de Desenvolvimento do Turismo. Disponível em: < http:// www.PRODETUR.ri.gov.br/ >. Acessado em abril de 2019.

Raulino, S. F. (2013). Injustiças Ambientais e Indústria do Petróleo: temor e consentimento nas representações de populações que sofrem efeitos de proximidade da refinaria Duque de Caxias (REDUC). Revista de Educação, Ciências e Matemática. 3 (3), 70-90. Disponível em: < http://publicacoes.unigranrio.edu.br/index.php/recm/ article/view/2548/1185

Sebrae/RJ, Serviço Brasileiro Apoio às Micro e Pequenas Empresas/Rio de Janeiro. (2018). Plano Estratégico da Região Turística - Baixada Verde. Rio de Janeiro: SEBRAE/RJ, 2018.

\section{Notas}

[1] A Baixada Fluminense é uma das maiores concentrações urbanas do Brasil e da América Latina. Em 2018, a estimativa populacional, segundo o Instituto Brasileiro de Geografia e Estatística (IBGE, 2018), alcançava 3.867.923 habitantes. Para se ter uma ideia, São João de Meriti comporta o maior número de habitantes por quilômetro quadrado da América Latina e o segundo maior do mundo, sendo conhecido como o "Formigueiro da América Latina (IBGE, 2010).

[2] Para compreender melhor as áreas estratégicas de investimento no estado, consultar o portal do PRODETUR/RJ disponível em http://www.PRODETUR.rj.gov.br/objetivo.asp em que fica evidente o investimento de dois polos (Litoral e Serra).

[3] Belfort Roxo, Duque de Caxias, Japeri, Magé, Mesquita, Nilópolis, Nova Iguaçu, Queimados, São João de Meriti e Seropédica.

[4] Sobre isto, a Secretaria de Turismo do Estado do Rio de Janeiro (SETUR) constatou que a região metropolitana do Rio de Janeiro mantém 36,27\% de seu território verde conservado. Deste total, 10,96\% - cerca de um terço - estão localizados nos 13 municípios que integram a Baixada Fluminense.

[5] O PRT foi considerado estratégico para a consecução da Política Nacional de Turismo 2002-2007, que tinha a premissa de atuar de forma descentralizada e regionalizada. As avaliaçóes feitas sobre o PRT mantiveram a proposta da regionalização que havia sido incorporada ao Plano Nacional de Turismo 2013-2016 e se mantiveram no Plano Nacional de Turismo 2018-2022 (MTur, 2007; MTur, 2013; MTur, 2018).

[6] Projeto intitulado: “Observatório do Turismo da Região Turística Baixada Verde”: a extensão universitária para o fomento do desenvolvimento regional. Programa de Bolsas Institucionais da UFRRJ BIEXT/2017 